\title{
CARACTERIZANDO A ATIVIDADE DO PESQUISAR NA ÉPOCA DE SUA INTRODUÇÃO: SEGUNDO DEPOIMENTOS DE ENFERMEIRAS ${ }^{1}$
}

CHARACTERIZING RESEARCH ACTIVITY BY THE TIME OF ITS INTRODUCTION: NURSES REPORTS.

Waleska Zafred Ricci ${ }^{2}$

\begin{abstract}
RESUMO: $O$ interesse em desenvolver este trabalho surgiu a partir de trabalho anterior (Ricci,1994) que versou sobre o significado da pesquisa científica para alunos dos Cursos de Farmácia e Enfermagem. Após a conclusão deste houve a necessidade de conhecer a evolução histórica da pesquisa científica destacando a época e fatores predisponentes ao seu desenvolvimento. Tem-se como objetivo reconstituir a evolução histórica da pesquisa em enfermagem, buscando em que momento houve seu desenvolvimento na profissão, e identificar os reflexos da introdução da pesquisa no ensino e assistência na opinião de enfermeiras docentes. Para realizar a coleta de dados foi utilizada a entrevista semiestruturada. A população deste estudo foi composta por enfermeiras docentes que vivenciaram a época de 60/70. A princípio obteve-se uma lista com o nome de nove enfermeiras, mas, de acordo com o referencial teórico, no decorrer das entrevistas foram de saturando os dados obtidos e a amostra final constou de 4 enfermeiras. Apresenta-se a definição dos temas gerados a partir da análise dos depoimentos das enfermeiras. A análise realizada possibilitou a descoberta de dois temas: INICIANDO A PESQUISAR, TENDO NECESSIDADE DE SE ATUALIZAR. Os dados revelaram as dificuldades que as enfermeiras-docentes vivenciaram na época coincidente da introdução da pesquisa e da pós-graduação. Observamos que as colocações apresentadas por aquelas enfermeiras são as mesmas colocadas hoje pelas enfermeiras assistenciais que desejam realizar investigação (Cassiani, 1994). Entretanto a diferença fundamental está no fato de que para as docentes houve exigência e para as assistenciais parte-se de uma necessidade interna que nem sempre encontra apoio e estímulo do serviço.
\end{abstract}

UNITERMOS: Pesquisa em enfermagem - Evolução histórica.

1 Este trabalho foi orientado pela Professora Doutora Silvia Helena de Bortoli Cassiani do Departamento de Enfermagem Geral e Especializada da EERP-USP e Tutora do Programa Especial PET-CAPES.

${ }^{2}$ Graduanda da Escola de Enfermagem de Ribeirão Preto - USP e Bolsista do Programa Especial de Treinamento PET-CAPES, autora deste trabalho. 


\begin{abstract}
My interest in developing this study came from a previous work (Ricci, 1994) about scientific research meaning for Pharmacy and Nursing students. After its conclusion, it was necessary to know scientific research historical evolution pointing out the epoch and factors which contributed for its development. Aiming at reconstituting Nursing research historical evolution, trying to find the moment of its development in the profession, identify the reactions research introduction in the course and the assistance in opinions of docent nurses. For this, a semi-structured interview has been used. The population for this study was of nurses who lived the 60 's and 70's. At first I obtained a list of nine names of nurses, but according to the theoretical reference, data became saturated along the interview, therefore the final sample was of only four nurses. The definition of generated themes from nurses speeches analysis was presented. The analysis allowed the discovery of two themes: STARTING ON RESEARCH and NEEDING REFRESH. The data revealed the difficulties that the docent nurses experienced by the time of research and postgraduation introductions. It has been observed that the arguments used by those nurses are the same used today by assistance nurses who want to investigate (Cassiani, 1994). However, the main difference lays on the fact that for the docent nurses there was a demand and for the assistance ones there is an internal need that not always is appraised and stimulated in service.
\end{abstract}

KEYWORDS: Research in nursing - Historical evolution.

\title{
INTRODUÇÃO
}

O interesse em desenvolver este estudo surgiu a partir da realização de trabalho anterior (Ricci,1994) que versou sobre o. significado da pesquisa científica para os alurıos dos Cursos de Farmácia e Enfermagem. Após a conclusão deste houve a necessidade de conhecer a evolução histórica da pesquisa científica destacando a época de inserção e fatores predisponentes ao seu desenvolvimento.

Observamos que algumas escolas de enfermagem têm a preocupação de ampliar cada vez mais os horizontes da pesquisa científica em um movimento de reflexão científica de alunos de graduação, pós-graduação, docentes e também enfermeiros que desenvolvem trabalhos científicos, quer sejam eles bolsistas de iniciação científica ou pós-graduandos para obtenção de titulação acadêmica.

Como bolsista de iniciação científica e pela curiosidade inicial de verificar a evolução histórica da pesquisa científica em enfermagem e os reflexos desta para a prática assistencial, planejamos este estudo tendo os objetivos de: reconstituir a evolução histórica da pesquisa em enfermagem, buscando o momento de sua inserção na profissão e o de identificar os reflexos desta no ensino e na assistência, segundo a opinião de enfermeiras e/ou docentes que vivenciaram a época de introdução dos cursos de mestrado. 


\section{EVOLUÇÃO HISTÓRICA DA PESQUISA NA ENFERMAGEM}

Torna-se, pois, necessário investigar as origens da pesquisa, procurando saber como nela se processou a iniciação das enfermeiras e qual a sua repercussão na assistência, uma vez que a Enfermagem vivencia atualmente uma explosão em termos de produção científica.

Pode-se dizer que o início da pesquisa científica na Enfermagem foi com Florence Nightingale, através do seu hábito de registrar observações e analisar os dados obtidos. No Brasil, as Escolas de Enfermagem tiveram início na década de 20/30. Entretanto, nessa época, as pesquisas eram escassas e as enfermeiras não tinham preparo para tal (Mendes, 1991).

Acresce-se o fato de que nessa época o único periódico nacional era a Revista Brasileira de Enfermagem, criada pela ABEn (Associação Brasileira de Enfermagem), em 1932, cuja temática dos artigos girava em tomo de estudos de casos, prática assistencial, recursos, administração e educação em enfermagem.

Já na década de 50, é importante citar o Censo de Enfermagem, considerado como primeiro trabalho científico documentado na área, e o "Levantamento de Recursos e Necessidades de Enfermagem", em 1956/58.

Outro ponto de referência da solidificação científica da enfermagem brasileira foi a tese de cátedra, defendida por Glete de Alcântara da Escola de Enfermagem de Ribeirão Preto - USP, em 1963, intitulada "A Enfermagem moderna como categoria profissional: obstáculos à sua expansão na sociedade brasileira"; foi considerada a primeira tese em Enfermagem no Brasil.

Evento considerado relevante foi o XVI Congresso Brasileiro de Enfermagem, realizado no ano de 1964, em Salvador, que teve como tema central "Enfermagem e Pesquisa". Pôde-se ainda verificar, de 1964 até a década de 70, um aumento na motivação pela pesquisa através de um acréscimo na sua produção. Portanto, observa-se que a pesquisa em enfermagem intensificou-se no final da década de 60 , devido à:

1 - reforma universitária obrigando os docente à titulação mínima de mestres e doutores;

2 - criação dos cursos de pós-graduação em Enfermagem, em nível de mestrado, para atender exigências do ensino superior;

3 - introdução e incrementação da educação superior de enfermagem e o aumento do número de escolas de enfermagem.

Eventos significativos para a área no que concerne à temática da pesquisa serão destacados.

$\mathrm{Na}$ década de 70, com o ingresso da enfermagem no sistema nacional de pós-graduação, vários cursos de mestrado foram criados em diversas Escolas de Enfermagem do pais, talvez um dos fatos mais importantes. Tal década foi marcada por um aumento do número de trabalhos, ou seja, publicações na Revista Brasileira de Enfermagem: 505, de 1970 a 1981, contra 28, até 1970 (Cassiani,1987). 
A diretoria da ABEn, presidida por Glete de Alcântara no período de 1972/76, promoveu a reforma dos Estatutos da Associação e estabeleceu que o CEPEn seria o órgão da $A B E n$ destinado a incentivar e oferecer recursos para a pesquisa na área.

Em 1974, foi proposta a criação do CEPEn (Centro de Estudos e Pesquisa em Enfermagem), que se efetivou em 1978.

Em 1979, com a necessidade de criar espaços para discussões sobre pesquisa (uma vez que esse assunto não mais havia sido tema oficial de congresso, depois de 1964), bem como a necessidade de analisar os rumos da pesquisa na enfermagem, o CEPEn organizou o I Seminário Nacional de Pesquisas em Enfermagem (SENPE), em Ribeirão Preto.

O primeiro curso de pós-graduação, em nível de doutorado, foi criado em 1981, pelas duas Escolas de Enfermagem da Universidade de São Paulo e a seguir o Departamento da Escola Paulista criou o doutorado em Materno-Infantil.

Em março 1982, em Brasília, aconteceu o II SENPE, que teve como propósito avaliar tanto a pesquisa em enfermagem quanto o ensino de pós-graduação. $E$ a evolução da pesquisa continuou sendo avaliada em 1984, com o III SENPE, que teve como objetivo "estudar as alternativas de interpretação metodológica e analisar sua utilização na produção científica da enfermagem (Anais,1984)".

O IV SENPE, em 1985, continuou tendo corno objetivo a análise da produção científica da enfermagem, as tendências e perfis metodológicos da pesquisa. $E$ o seguinte, em 1988, objetivou incentivar o interesse dos enfermeiros assistenciais pela pesquisa, tendo como tema central " Pesquisa e Serviço de Enfermagem ".

Na década de 90, houve o estabelecimento de publicações como a Revista Latino-americana, Revista Texto \& Contexto e o desenvolvimento de outras como: Revista da Escola de Enfermagem, Revista Baiana, Revista Gaúcha de Enfermagem, entre outras.

Além disto, pode-se afirmar que já existe um número relativo de mestres e doutores em enfermagem em várias áreas do país e observa-se um movimento crescente das enfermeiras assistenciais na procura de cursos de pós-graduação.

A seguir passaremos a tratar dos reflexos da introdução da pesquisa no ensino e assistência.

\section{REFLEXOS DA INTRODUÇÃO DA PESQUISA NO ENSINO E ASSISTÊNCIA.}

O reconhecimento da organização científica da Enfermagem no Brasil, teve inicio a partir da aprovação da carreira universitária em 1963, evoluindo sobremaneira a partir de 1972, ano que se constituiu num marco de crescimento, pelo surgimento dos Cursos de Pós-Graduação. É a partir da década de 1970, com a criação dos Cursos de Pós-Graduação, que a pesquisa é assumida como um compromisso da Enfermagem, vinculada efetivamente ao sistema de ensino, mas sem vinculação formal com o sistema assistencial (Westrupp,1994). 
Pode-se afirmar que a pesquisa, hoje em dia, enquanto processo distanciado da prática, passa a ser vista como uma tentativa frustrante, esparsa e não convincente, pelo menos para aqueles que estão na lida cotidiana do cuidar. Nesta perspectiva, a pesquisa não se destina à sua finalidade maior que é o seu compromisso com a transformação da realidade social - política - econômica ecológica, com vistas à melhor qualidade de vida dos seres humanos e do planeta.

Sabendo da importância da pesquisa em enfermagem e sua influência na prática, faz-se necessário rever como a pesquisa começou a influenciar ou não as questões da prática asssitencial de enfermagem.

$\mathrm{Na}$ década de 50 e 60, as enfermeiras eram preparadas para servir, para dar assistência direta ao paciente. A pesquisa era um ideal longínquo, que embora interessados em realizá-la não tinham conhecimento para tal (Minzoni,1980).

Durante essa época todo docente atuava como enfermeiro-assistencial, o que trazia maior facilidade entre o ensino teórico-prático bem como maior respeito e aceitação por parte da Instituição à qual estavam inseridas.

Posteriormente, como o interesse em desenvolver pesquisa aumentou, face à obrigação advinda da reforma universitária, tornou-se imprescindivel pesquisar e a pesquisa passou a ser mais uma meta dos docentes.

É importante salientar que, apesar de gerar conhecimento e reconhecimento enquanto ciência, trazendo inovações para a assistência, a pesquisa trouxe para - ensino mudanças ainda questionadas, pois o docente tomou-se um conhecedor afastado da realidade hospitallar: Será que essa distância não está trazendo implicações no ensino dos futuros enfermeiros ? Será que o interesse pela pesquisa superou o da assistência ? Quais as causas que levaram ao contexto atual da enfermagem, no que se refere à ruptura entre o ensino e a assistência de enfermagem ? Tais questões nortearam o desenvolvimento deste estudo.

\section{REFERENCIAL METODOLÓGICO}

Com a finalidade de obter uma compreensão mais próxima do real da experiência vivida pelas enfermeiras, optou-se pelo método qualitativo de pesquisa, que, segundo Taylor, Bogdan (1984), se refere num sentido mais amplo à pesquisa que produz dados descritivos: palavras escritas ou faladas pelas próprias pessoas e seus comportamentos observáveis. Métodos qualitativos são usados para descobrir o que há por trás de um fenômeno que é pouco conhecido. Esses métodos são considerados humanisticos: o pesquisador olha para $o$ ambiente $e$ as pessoas holisticamente. Referem-se tanto às pesquisas sobre a vida, estórias e comportamentos de pessoas. 
Triviños apud Bogdan (1990) descreve as cinco características básicas da pesquisa qualitativa.

1. A pesquisa qualitativa tem o ambiente natural como fonte direta dos dados e o pesquisador como instrumento-chave.

2. A pesquisa qualitativa é descritiva.

3. Os pesquisadores qualitativos tendem a analisar seus dados indutivamente.

4. Os pesquisadores qualitativos estão preocupados com o processo e não simplesmente com os resultados e o produto.

5. O significado que as pessoas atribuem à vida e às coisas são a preocupação essencial na abordagem qualitativa

Um dos referenciais teóricos da pesquisa qualitativa é a TEORIA FUNDAMENTADA NOS DADOS, o qual estamos iniciando o seu estudo e pretendemos utilizá-la nesta investigação.

\section{PROCEDIMENTOS DA PESQUISA}

\section{A população}

Frente aos objetivos da investigação e para que houvesse respostas às questões norteadoras, a população investigada constituiu-se por enfermeiros docentes-assistenciais que, na época de 1970, vivenciaram a introdução da pesquisa científica. Em vista disso, é importante salientar que todos os entrevistados encontram-se, atualmente, na situação de aposentado.

Por intermédio de uma docente que havia vivenciado essa época, foi possivel adquirir a relação de outras atuantes naquele período. Seguindo esta orientação, foi obtida um listagem através da Seção de Pessoal da EERP-USP dos docentes que preenchiam os requisitos para este estudo.

A lista constava de nove (9) docentes. Inicialmente era objetivo entrevistar as nove (9) docentes, entretanto, na quarta entrevista, os dados já estavam saturados.

Face a isso, a amostra final constou de quatro (4) enfermeiras, sendo que uma atuou na prática de enfermagem, apenas enquanto como supervisora de estágio.

As enfermeiras foram contatadas pelo telefone e, após ter sido explicado o intuito desta investigação, convidadas a fazer parte da amostra.

Havendo concordância, era combinado o dia e o horário para a realização da entrevista. Das cinco enfermeiras contatadas, apenas uma (1) não mostrou disponibilidade para a entrevista. 


\section{A entrevista}

Neste trabalho utilizou-se a entrevista semi-estruturada, vindo de encontro com as necessidades da pesquisa qualitativa. Todas as entrevistas foram realizadas pela autora, tendo sido formulado um roteiro de questões contendo perguntas abertas, que servia apenas como fio condutor da entrevista.

Ao longo das entrevistas, quando se sentiu necessidade de maiores esclarecimentos, novamente voltava a questão para a entrevistada.

Como a experiência enquanto entrevistadora estava se iniciando, na primeira entrevista, pelas dificuldades em retomar 0 assunto, obteve-se no final um volume grande de dados e o tempo gasto foi maior nesta entrevista do que nas posteriores.

Isso despertou para a necessidade de algumas vezes retornar a questão, o que aconteceu nas entrevistas subseqüentes.

Ao início de cada entrevista, a fita era testada, informando o dia e hora. Após a concordância do entrevistado para a gravação, iniciava-se as entrevistas.

Todos os dados foram transcritos integralmente pela pesquisadora e o tempo total gasto nas entrevistas foi de cinco horas e na transcrição foi de vinte e oito horas.

\section{ANÁLISE DOS DADOS}

A análise centrou-se no significado da introdução da pesquisa na década de 70 para as enfermeiras docentes que vivenciaram aquela época. A estratégia utilizada para a análise foi a das fases da pesquisa qualitativa e para tanto foi utilizada a teoria fundamentada nos dados, preconizada por Glaser \& Strauss(1967) e descrita por Cassiani (1994).

Após terminada as transcrições das fitas, checava-se a transcrição, a fim de obter a veracidade desta.

A seguir, iniciou-se a fase de codificação dos dados. Foram feitas várias leituras a fim de identificar o que era pertinente para o estudo; desta forma os dados foram destacados do texto e se Ihes atribuiu um significado, como mostra o quadro abaixo.

\begin{tabular}{l|c}
\hline DISCURSO DA ENFERMEIRA & CÓDIGO \\
"... com essa demanda de alunos da pós- & Influenciando a prática de enfermagem \\
graduação, de enfermeiros de campo, eu & \\
acredito que vai ter um reflexo melhor da & \\
pesquisa no campo. As pesquisas vão & \\
influenciar a prática de enfermagem, na & \\
qualidade da assistência." &
\end{tabular}


Após destacado o código nas descrições, segue-se a fase seguinte agrupamento das falas com o mesmo significado.

\begin{tabular}{l|l}
\hline \multicolumn{1}{c|}{ CÓDIGO } & \multicolumn{1}{c}{ CATEGORIA } \\
$\begin{array}{l}\text { 1. tendo urgência em iniciar pós-graduação } \\
\text { 2. sendo pressionada para fazer mestrado } \\
\text { 3. fazendo pós-graduação para ser recontratada } \\
\text { 4. tendo que ter mestrado para ser recontratada } \\
\text { 5. sendo pressionada a crescer } \\
\text { 6. tendo prazos para terminar a pesquisa }\end{array}$ & $\begin{array}{l}\text { Tendo necessidade emergente em } \\
\text { pesquisar }\end{array}$ \\
\hline
\end{tabular}

Para a análise indutiva é necessário reunir o maior número possível de códigos. Foi processado outro agrupamento, o das categorias reunidas, como é demonstrado abaixo.

1. iniciando a pesquisa

2. tendo necessidade emergente de pesquisar

3. tendo dificuldades com a pós-graduação

O passo seguinte foi a formação de temas, através do agrupamento das categorias relacionadas a um aspecto comum. Os temas comportam códigos comuns a todas as descrições.

\begin{tabular}{l|l} 
CATEGORIA REUNIDA & TEMA \\
& PESQUISANDO NA DÉCADA \\
DE 70 \\
sobre a Integração Docente-assistencial &
\end{tabular}

\section{APRESENTAÇÃO DOS RESULTADOS}

Nesta fase, apresenta-se a definição dos temas gerados a partir da análise dos depoimentos das enfermeiras. A análise realizada possibilitou a descoberta de dois temas: INICIANDO A PESQUISAR, TENDO NECESSIDADE DE SE ATUALIZAR.

O primeiro fenômeno Iniciando a pesquisar indica a necessidade de fazer mestrado para ser recontratada, enfoca detalhes sobre a pesquisa na década de 70 e ainda dificuldades em realizar pós-graduação num momento em que a Reforma Universitária urgia essa necessidade.

Dentro deste contexto surge o fenômeno Tendo necessidade de se atualizar, que representa a enfermeira que está na prática há vários anos, sente-se desatualizada com a base teórica, retornando à escola para suprir esta dificuldade com a teoria. 
FENÔMENO 1: INICIANDO A PESQUISAR

O fenômeno Iniciando a pesquisar mostra como caminhava a pesquisa e pesquisadores, na década de 70 . Apresenta a evolução histórica da pesquisa em enfermagem, os fatores facilitadores e bloqueadores desta evolução, a dificuldade em realizar pós-graduação, quando era ainda desconhecida por muitos.

O fenômeno está demonstrado nas seguintes categorias:1) Iniciando a pesquisa; 2) Tendo necessidade emergente de pesquisar; 3) Tendo dificuldades com a pós-graduação. As falas abaixo exemplificam as categorias citadas acima:

"... Mas era uma exigência da universidade, ela estava exigindo que as pessons fizessem um curso de mestrado." (2)

"... O início da pesquisa na Enfermagem foi coletando dados para as pesquisas de docentes."

"Eu me matriculei em 72 na Escola de Enfermagem Ana Nery, eu não sabia o que leviar para a pós-graduação, pois eu não sabia o que era pósgraduação" (1)

\section{A. INICIANDO A PESQUISA: DESTACANDO FATORES QUE INFLUENCIARAM O INÍCIO DA PESQUISA}

A categoria Iniciando a pesquisa, além de refletir a época de 70, mostra também os fatores que influenciaram essa época.

\section{1) Década de 70: voluntariado de pesquisa}

A categoria Década de 70: voluntariado de pesquisa nos mostra que as enfermeiras pesquisaram por disponibilidade própria, fazendo trabalhos sozinhas com alguma orientação, mas não havendo obrigatoriedade de pesquisar.

"Fazia pesquisa na década de 70 quem quisesse, quem tinha uma tendência, quem quisesse gastar um tempo pesquisando alguma coisa." (1)

Além da iniciativa própria, havia também o interesse dos docentes que estavam começando a recrutar alunos para auxiliar nas pesquisas, sendo assim um aprendizado.

"Era voluntário, a gente trabalhava fora do horário da escola. Então a gente tinha alguma orientação, o que era um pesquisa, porque a gente precisa coletar com certa fidedignidade, pois os dados iam ser para pesquisas de docentes. . . "(2)

Por ser uma atividade desconhecida, era amedrontadora para as enfermeiras.

\section{2) Vivenciando a pesquisa como um bicho de sete cabeças}

Em conseqüência dessa atitude de realizar pesquisa voluntariamente, os pesquisadores não tinham fundamentação teórica, pois pesquisa era algo novo e sem obrigatoriedade, o que refletiu em conceituar a pesquisa como um "bicho de sete cabeças ", não se sabia como realizá-la. 
"Nesta época, no começo a gente não entendia até muito bem o que era a pesquisa cientifica, a gente achava que pesquisa cientifica era um bicho de sete cabeças... " (2)

Além de ser algo novo, as informações não circulavam e os cursos não preparavam os docentes.

\section{3) Não tendo informaçōes sobre pesquisa científica na década de 70}

Além dos preconceitos acerca da pesquisa, havia grande desinformação de como fazer pesquisa nessa época, mesmo porque o que se sabe é que nesse período o Brasil não contava com grande desenvolvimento científico, e ainda o único periódico nacional exclusivo da Enfermagem, era a Revista Brasileira de Enfermagem.

"A gente não sabia nem o que era pesquisa em enfermagem, nem o que era pesquisa em área nenhuma ou o que era pesquisa ou como se fazia pesquisa e ninguém estavia voltada para este aspecto na décala de 70, 110 Brasil, principalmente. "(1)

Em contrapartida, havia também uma busca, por parte daqueles docentes que estavam iniciando a pesquisa científica, para que pudessem aprender sobre essa "nova" atividade que estava iniciando.
"...Então saiu um trabalhinho aqui, um trabalhando ali, sob a orientação de um professor da Faculdade de Medicina de Ribeirão Preto - USP, en vivina querendo tirar as coisas, aprender com ele, e eu queria fazer um mestrado, queria fazer uma pesquisa... " (1)

Observa-se que há um volume considerável de trabalhos realizados nessa época caracterizado pela falta do rigor metodológico (Mendes, 1991). Apesar das circunstâncias terem trazido a necessidade da pesquisa na enfermagem, as enfermeiras não recebiam um conteúdo completo sobre o assunto durante a graduação, o que refletiu em pesquisas sem rigor metodológico.

"As pesquisas daquela época não era com esse rigor cientifico, que agora tem que ser, mas com o rigor assim de muito detalhe..." (3)

"Nós viamos ter trabalhos excelentes nas revistas de enfermagem antes da obrigatoriedade, era trabalhos simples, trabalhos talvez com a metodologia não tão teórica." (3)

"Pesquisa em 70, eu vejo como traços de pesquisa em enfermagem ou vejo a pesquisa em enfermagem emergindo. "(1)

\section{4) Vivenciando uma enfermagem que sempre pesquisou, mas nunca documentou.}

Por outro lado, verificou-se que, embora na década de 70 não houvesse problemas com verba, anterior a essa época, os recursos que existiam eram escassos, o que nos faz crer que a Enfermagem sempre pesquisou, no entanto não sabia e não havia recursos para registrar.

"A Enfermagem sempre pesquisou. O problema é que nunca documentou, a pesquisa faz parte do dia-a-dia do enfermeiro, o que houve em 70 foi a obrigatoriedade da universidade. A enfermagem sempre pesquisou, é verdade, semipre houve pesquisa. Tentou-se documentar o máximo que se 
pôde com os precários recursos que a gente tinlan, de falta de orientação, de falta de tempo, de' falta de material...

Concomitantemente com o surgimento dos órgãos financiadores de bolsas de pesquisas e a obrigatoriedade da pesquisa, surge também o governo exigindo toda documentação acerca dos projetos, ou seja, a burocracia começa a dificultar o desenvolvimento da pesquisa.

"Então a hurocracia dificultou o pesquisador. Então na década de 70/80 é
que a gente emerge como pesquisador, a gente tem toda disponibilidade para
pesquisar, a partir de 80, mas a gente tem toda uma burocracia para poder
pesquisar, que isso puxa a gente para trás, desanima o pesquisador." (1)

A categoria apresentada INICIANDO A PESQUISA mostra que a pesquisa na década de 70 iniciou-se como voluntariado, embora tendo muitas dúvidas e dificuldades acerca do assunto. Com isso, os primeiros trabalhos realizados eram sem rigor científico. Pelo fato desse número ser significativo, houve a preocupação em estabelecer normas e regras, surgindo, portanto, a metodologia científica com seu rigor metodológico, caracterizando os trabalhos realizados a partir dessa época.

\section{B. TENDO NECESSIDADE EMERGENTE EM PESQUISAR: CONTEXTO VIVENCIADO NA ÉPOCA DO AUGE DA PESQUISA}

A década de 80 foi marcada por uma forte imposição da Universidade sobre os docentes, o que os levou a pesquisar sem opção de escolha.

Com a reforma universitária e a implantação dos cursos de pós-graduação, a enfermeira/docente foi pressionada a pesquisar em curto prazo de tempo, precisando ainda fazer pós-graduação para ser recontratada.

\footnotetext{
"A gente tinha uma certa urgência em fazer pesquisa porque a unizersidade já estav'a começando a exigir a pós-graduação. "(2)

"Não sei se a gente queria fazer a pós-graduação, ou deveria fazer para ser recontratada ou z'ocê perdia o emprego. "(1)

"Eu, pelo menos, fui contratada em 69, mas para renozar o meu contrato, eu tinha que ter mestrado, para ser recontratada eu tinlla que estar matriculada em um curso de pós-graduação." (1)
}

Nessa época, pudemos sentir que os docentes foram marcados por um forte sentimento de repressão à medida que tinham de cursar a pós-graduação, se quisessem continuar na Escola como docente.

"Eu entrei num esquema de ter que fazer pós-gradunção e tive muita dificuldade."(3)

"Mas era exigência da Universidade, ela estaz'a exigindo que as pessoas fizessem um curso de mestrado. "(2)

$\mathrm{Na}$ época da reforma universitária, houve grande pressão sobre os docentes para que eles crescessem enquanto pesquisadores, pois a universidade estava cobrando que eles fizessem pós-graduação, ou saiam da escola. Além da reforma universitária, houve também, como fator de imposição para realização do mestrado, a criação dos cursos de pós-graduação como também a introdução 
e incrementação dos cursos superiores de enfermagem, bem como o aumento do número de ingressantes nas Escolas de Enfermagem.

"Então enquanto docente a gente é obrigado a crescer porque ou eu sou professor titular ou estou no olho da rua (1)".

"A enfermeira que eu sou hoje não é a mesma que eu fui em 69, fui obrigada a crescer pela própria USP, a gente foi obrigada a crescer nem que a gente não quisesse, a gente tinha que crescer (1)".

"A Universidade de São Paulo me obrigou a fazer mestrado, doutorado, livre-docente, titular não porque eu sou bonitinla porque esse tipo de coisa fomenta, cresce a universidade, amplia, veja nós temos uma escola de graduação e outra de pós-graduação. Nós temos uma formação, a coisa cresce, não morre (1)".

Mediante todos estes fatores, quem dirigia a carreira acadêmica do docente era a própria universidade; então em 70/80 vamos ter uma Universidade que tomou conta do docente, obrigando a fazer o que era melhor para ele, mas que trouxesse grandes benefícios para ela própria.

"Então a partir do novo estatuto da USP, você tinlua aí uma universidade que tomavia conta de você (1)".

Com todo esse cenário, o docente, além de desenvolver um projeto de pesquisa que primeiramente Ihe foi imposto, vivenciava agora uma luta contra o tempo, ou seja , ele tinha prazos para desenvolver e entregar seu trabalho.

"E com a pesquisa, e se você está em uma pós-graduação, a pós-graduação e a própria USP começaram a te cobrar prazos, então você não deve ficar a vida inteira fazendo um mestrado ou doutorado. Você tem que terminar o seu mestrado e o doutorado. Então foram cobranças e mais cobranças (1)".

Em conseqüência dessa busca dos profissionais em realizar trabalhos científicos, tomou-se a postura de se estabelecer bases teóricas a fim de tornarse único o método de fazer as pesquisas, e assim surge a metodologia científica com todo seu rigor.

“Mas o rigor metodológico começou com a pesquisa no final da década de 70, e eu digo, até a partir de 80, porque na nossa escola foi criada no final de 70. Então os frutos dessa pós-graduação começou a aparecer em 80 (1)".

"Eu poderia ter publicado em 70 o dobro do que eu publiquei, mas eu publiquei só a metade, que a gente era muito rigorosa, a gente era muito rigorosa com a gente mesmo, então a gente só queria publicar aqueles trabalhos perfeitos, o bom, o mais ou menos, a gente jogava fora (1)".

Com o estabelecimento das normas de metodologia científica, e também com a obrigatoriedade da pesquisa, começou a haver por parte dos órgãos governamentais interesse em financiar os projetos de pesquisa, como, por exemplo, CNPq, FAPESP, entre outros.

"Então houve mudança da realidade nacional, a pós-graduação mudou a nível nacional, obrigou a todos os profissionais a pesquisarem e dentro de uma estrutura, que era a pós-graduação, o que trouxe as agências 
financiadoras de pesquisa, FINEPS, CNPq, e outras, FAEPA no Hospital das Clínicas, e PET (1)".

Com essa nova investida do governo, observa-se que nesta época não havia dificuldades com verbas financeiras para a pesquisa.

"Naquela época com verba de pesquisa, eu não precisava me preocupar. A verba que a USP oferecia aos Departamentos, era a verba que eles davam dinheiro para comprar meios e recursos didáticos para os alunos de graduação, e o pessoal que pesquisava era tão pouco, que da sobra do material didático para os alunos a gente poderia fazer os nossos trabalhinhos $(1)^{\prime \prime}$.

A categoria apresentada TENDO NECESSIDADE EMERGENTE EM PESQUISAR, mostra em quais circunstâncias os docentes iniciaram a pesquisar. Embora a docente acreditasse na importância de desenvolver pesquisa, não só porque ela faz parte da profissão ou porque é obrigatória nos trabalhos finais de dissertação ou tese, mas porque, em nosso ver, as enfermeiras começaram a sentir necessidade de buscar a assistência de enfermagem em conhecimentos mais sólidos e teóricos e não somente na tradição, como era o costume.

\section{TENDO DIFICULDADES COM A PÓS-GRADUAÇÃO: CONSEQÜÊNCIA EM CURSAR UMA PÓS-GRADUAÇÃO AINDA IMATURA}

O docente encontrava-se em um momento em que ele queria cursar a pósgraduação para seguir carreira universitária e, por outro lado, era obrigado para tal.

Embora a pesquisa seja considerada inerente à pós-graduação, é preciso ter em mente o fato de que a pós-graduação, como um todo, não derivou de um processo expontâneo de crescimento da produção científica e do aperfeiçoamento na formação de seus quadros, mas de uma política deliberada do Estado, onde se institucionalizou a pós-graduação (Elsen, 1994).

Portanto, a imposição da pesquisa para os docentes e o desenvolvimento da pesquisa em uma época em que ainda não estava totalmente estruturada, trouxe dificuldades aos docentes no decorrer do curso de pós-graduação.

\section{1) Instituindo a pós- graduação}

A necessidade de fomentar a Universidade aumentava; criou-se, portanto, o novo Estatuto da USP em 1969, em que uma das maiores metas foi a institucionalização da pós-graduação para a enfermagem.

"Eu me lembro também na década de 70, a mudança do estatuto da Universidade de São Paulo de 69, que começou a instituição da pósgraduação (1).

"Isso também refletiu na divisão, a instituir-se a pesquisa, institucionalizouse a pesquisa em enfermagem, ela virou uma obrigatoriedade". 


\section{2) Não sabendo o que era pós-graduação}

Devido ao fato de que houve uma explosão de pós-graduação, os docentes viram-se obrigados a pesquisar em mínimos prazos de tempo; portanto, este docente foi para a pós-graduação sem saber o que iria encontrar, nem o que precisava ter ou levar para iniciar o curso.

"Me matriculei em 1972, na Escola Ana Nery, eu não sabia o que levar para a pós-graduação, pois eu não sabia o que era pós-graduação (1)".

\section{3) Vivendo dificuldades no início da pós-graduação}

A enfermeira não estava habituada a registrar suas informações, ou ainda não tinha o hábito da leitura, estava mais ligada à pratica assistencial, o que caracterizava essa época. Portanto, começar a pesquisar repentinamente tornou-se uma tarefa dificil. A pós-graduação estava ainda sendo estruturada, e a Escola Ana Nery era o primeiro curso de pós-graduação do país, o que trouxe, tanto para os organizadores do curso quanto para os docentes que realizaram essa pós-graduação, dificuldades na sua realização.
"A área de pesquisa na própria pós-graduação na Escola Ana Nery, não era uma coisa já estabelecida, a gente tinla dificuldades (1)".
"Essa é uma parte falla do meu curso de pós-graduação, a parte das disciplinas eu não achei que foi falla não, mas a parte das orientações de pesquisa, eu achei que foi muito fallu, porque a minlı orientadora pegou o título de orientadora do traballo, porque tive que pôr no traballho com sendo orientadora, e na realidade não foi ela quem orientou o traballo, foi outra $\operatorname{pessoa}(2)^{\prime \prime}$.

\section{4) Tendo dificuldades enquanto pesquisador}

Esse início do desenvolvimento da pesquisa pelos docentes, trazendo várias dificuldades implicou em uma reflexão, questionando o seu potencial enquanto pesquisadora e o quanto tais imposições provocaram questionamentos dos mais diversos possiveis, submetendo as docentes e a enfermeiras a idéias préconcebidas.

\footnotetext{
"Então fica assim, aquelas que estão lá são burras, não pesquisam, não sabem nada. As que estão aqui, não sabem enfermagem, só sabem pesquisar Então eu achei isto horrível, eu tive muita dificuldade, até demorei muito para fazer o meu mestrado (3)".

"Eu tive muito problema com isso, de me aceitar como pesquisadora (3)".
}

A categoria apresentada TENDO DIFICULDADES COM A PÓS-GRADUAÇÃO relata uma época em que houve imposição por parte do Governo e Universidade para cursar a pós-graduação, com o novo Estatuto de 69 da Universidade de São Paulo, o que causou grandes dificuldades e questionamentos pelos docentes, acrescido das falhas de um curso que ainda não estava estruturado completamente, pelo fato de ser o primeiro curso de pós-graduação em enfermagem. 
FENÓMENO 2: TENDO NECESSIDADE DE SE ATUALIZAR CONTINUAMENTE

O fenômeno Tendo necessidade de se atualizar continuamente mostra a necessidade do enfermeiro em atualizar-se e a importância das instituições investirem no potencial do enfermeiro. O docente conseguiu posições de destaque, pois a Universidade destinou verbas para o crescimento do docente, não foi apenas incentivo interior, mas também exterior Segundo Mendes (1991), fica claro que as exigências de qualificação acadêmica para acesso bem como para progressão na carreira universitária, e o incentivo financeiro por parte dos órgãos governamentais, foi o fator de impulsão para o desenvolvimento da pesquisa em enfermagem e para o preparo de pesquisadores neste país.

O fenômeno está demonstrado nas seguintes categorias:

1 Precisando investir no enfermeiro;

2) Pesquisar provocando mudanças na assistência e ensino.

\section{As citações abaixo exemplificam as categorias acima.}

\footnotetext{
"Os outros hospitais, a instituição tem que achar alguma vantagem, querer investir no enfermeiro, para ele não morrer, senão ele morre (1)".

"Toda pesquisa traz alguma mudança para o ensino. A pesquisa de um maneira ou de outra acaba trazendo alguma mudança (2).
}

\section{A. PRECISANDO INVESTIR NO ENFERMEIRO}

A categoria Precisando investir no enfermeiro mostra que a enfermagem atual precisa de subsídio a fim de que os enfermeiros se atualizem, e para que a Enfermagem não seja caracterizada apenas por atendentes. A situação ainda parece ser a mesma, não obstante a evolução havida da lá para cá com o engajamento de, pelo menos, todos os docentes de Escolas de Cursos de Pósgraduação em nível de Mestrado e o conseqüente preparo dos mesmos para a elaboração de pesquisas. Se lembrarmos que os enfermeiros que desenvolvem pesquisa atualmente são recém formados, temos que convir que eles foram alunos de docentes cujo contato com a pesquisa era recente. É importante que essa minoria se transforme em toda a população de enfermeiros atuantes na prática, a fim de que a Enfermagem tenha uma inversão na sua realidade.

\section{1 ) Faltando investimento no enfermeiro}

O enfermeiro vivencia uma carga horária diária de seis horas dentro da instituição, não tem apoio da mesma para desenvolvimento de pesquisa científica, pois dentro de sua "rotina" não há tempo disponivel; portanto, o enfermeiro está precisando de um incentivo para crescer, da própria instituição que o emprega. Observa-se que o enfermeiro está querendo aprender mais, mas falta-lhe estímulo e incentivo. 
"Tá faltando que todos os hospitais, que todas as instituições que empregam o enfermeiro inzistam nele. Enquanto todas as instituições não quiserem investir, a enfermagem vai ficar com está. Esse investimento tem que trazer lucro para a instituição, senão ela não investe (1)".

"Agora para o enfermeiro não foi feita a escada. Eu acho que precisa algo maior que eu também não sei o que é, mas os hospitais precisam querer investir no seu enfermeiro, assim como a USP, que investiu no seu corpo. docente (2)".

\section{2) Necessidade de subsídios para o enfermeiro se atualizar.}

Pela falta de investimento por parte da instituição, observa-se uma necessidade de buscar recursos/subsídios para que este enfermeiro possa se atualizar, tanto teoricamente quanto na prática. A importância deste investimento para assistência de enfermagem, reverterá em benefícios para a própria instituição, além de benefício para o paciente.

"O enfermeiro não tem a obrigatoriedade de pesquisar, então não se exige isso do enfermeiro, então ele sai da Escola, ele pode ser um enfermeiro bom nos próximos 10 anos de formado, depois eu acho que deveria existir subsídios para ele se reciclar, se atualizar, ir a um congresso, ir a um curso de reciclagem, esse subsidio ninguém quer pagar nada (1)".

"Agora o enfermeiro, ele ainda é aquele barquinho. que ele tem a função assistencial, tem que dar a melhor assistência, não se criaram nada para ele, ele não pode pedir nada (1)".

\section{3) Vivenciando hoje uma enfermagem pobre}

Observa-se Que esta designação para a enfermagem atual é conseqüência da falta de verba e subsídio que o enfermeiro assistencial enfrenta, ou melhor, a própria enfermagem enfrenta. O despreparo do enfermeiro com relação à elaboração de pesquisa e à aplicação das pesquisas à prática e a falta de subsídios e verba para que ele se atualize nos mostra o quão precária e desatualizada está a profissão.

"Eu acho que ainda é uma enfermagem muito pobre, acho que ainda estamos nos tempos de Florence, e é só cuidar do paciente, não executa en fermagem de um aspecto científico, é ainda caracterizada por atendentes de enfermagem (2)".

"Ainda a enfermagem precisa crescer muito, uma enfermagem científica, não sei se é formar mais enfermeiros, se precisam se atualizar, a gente precisa de um método de trabalho, de um cientifiscismo para a enfermagem (2) ".

\section{4) Esperando uma inversão com a vinda da pós-graduação}

A vinda da pós-graduação trouxe grande esperança para que a Enfermagem consiga construir seu corpo de conhecimento próprio, esperando uma inversão 
na sua realidade atual, pois é sabido que a pós-graduação desempenha e desempenhou um papel fundamental na busca do conhecimento.

"O enfermeiro voltando para a pós-graduação, ele vai se interar desses assuntos, vai começar a ler pesquisa, ele vai aplicar as pesquisas. Eu acho que vai haver uma inversão, vai haver uma maior aceitação do pessoal assistencial com o pessoal docente. Acho que aí é que a pesquisa vai funcionar melhor (2)".

\section{B. PESQUISA PROVOCANDO MUDANÇAS NA ASSISTÊNCIA E NO ENSINO}

A categoria Pesquisa provocando mudanças na assistência e no ensino mostra a importância da pesquisa em enfermagem, uma vez que pesquisa científica é a atividade básica do ensino de pós-graduação e da profissão, e tem um compromisso social, que é a produção de conhecimento visando o bem-estar dos homens e do ambiente físico, econômico, político e social, portanto, provocando mudanças no ensino e na assistência.

\section{1) Pesquisa provocou mudanças, abrindo o raciocínio.}

A vinda da pesquisa na enfermagem foi notadamente importante, uma vez que trouxe mudanças tanto para o ensino quanto para a assistência; o que falta aos enfermeiros é a consciência do desenvolvimento da pesquisa, para a melhoria da qualidade de vida das pessoas.

"A pesquisa provocou mudanças, a enfermagem mudou muito e a pesquisa é a responsável por isso, parece que ela abre o raciocínio, obriga o raciocínio do profissional, quer enfermeiro ou outro, você faz uma pós-graduação, aprende um método científico, você vai posicionar-se desta forma organizada, científica, para o resto de sua vida profissional, e isto é muito bom (1)".

"Então a pesquisa levou à segurança, quanto mais a gente pesquisa, mais segurança vamos ter no ensino e na assistência (1)".

\section{2) Pesquisa modificando ensino e assistência}

Com o método científico, pôde-se organizar melhor a assistência de enfermagem agilizando assim a prática, bem como o ensino. Nota-se que a pesquisa viabilizou a assistência de enfermagem e o ensino.

"O reflexo da pesquisa para o ensino e assistência torna tanto um quanto a outra mais verdadeiros, dentro de um método científico, então você traz mais segurança (1)".

"Toda pesquisa traz mudanças para o ensino e assistência. Ela, de uma certa maneira, acaba trazendo mudanças, umas mais demoradas do que outras, mas ela traz de uma certa forma mudança para o ensino da enfermagem e até mudanças na prática da enfermagem (2)". 
"Com essa demanda maior de alunos de pós-graduação, de enfermeiro de campo, eu acredito que vai ter um reflexo melhor da pesquisa no campo. A pesquisa vai influenciar a prática de enfermagem na qualidade da assistência (2)".

A categoria Tendo necessidade de se atualizar mostrou a finalidade da pesquisa em enfermagem, trazendo mudanças no ensino e na prática assistencial, mas, para que isso seja possível, é fundamental investir no enfermeiro para que ele se atualize e possa trazer contribuições para a prática, melhorando assim a qualidade da assistência de enfermagem.

\section{DISCUSSÃO DOS DADOS}

Os dados revelaram as dificuldades que as enfermeiras-docentes vivenciaram na época coincidente da introdução dá pesquisa e da pósgraduação.

A Enfermagem necessitava de um novo caminho para que se tornasse uma profissão reconhecida, e com o advento da pesquisa surgiu uma nova esperança para tal. Visto que, na década de 70 , o início da pesquisa teve trabalhos sem rigor metodológico, houve então a necessidade de estruturar um padrão, segundo Oliveira (1964), "participando direta ou indiretamente de pesquisa, o importante é criar-se uma mentalidade nova na Enfermagem, uma mentalidade de que a devida afirmação profissional só ocorrerá, na proporção em que as próprias enfermeiras procurem uma melhor delineação da ciência da enfermagem, indispensável para o exercício de uma prática autêntica e eficiente. Para o desenvolvimento dessa mentalidade, cabe às Escolas de Enfermagem, nos cursos de graduação e pós-graduação, a responsabilidade de formar e especializar profissionais capazes de atuar numa sociedade em mudanças, compreendendo que esta mudança é motivada pela conquista que faz o homem em todos os ramos do saber e técnica".

Essa evolução implicou em um grande conflito, pois a enfermeira passou a desempenhar três papéis: docente, pesquisadora e enfermeira assistencial, acresce-se ao fato do desempenho de outros papéis como o de membro da sociedade, como participante da vida política e também papéis particulares (mãe, esposa, etc.). Neste novo contexto, a profissional foi obrigada a abandonar alguma das atribuições que the foram conferidas, e com isso a docente enfatizou mais a teoria, ou seja, aquela que ensina e pesquisa, afastada da assistência, com dificuldades de acompanhar a evolução da prática da assistência hospitalar.

Segundo Westrupp (1994), a prática assistencial é em si mesma, um modus morandis de pesquisa. No seu cotidiano se dá a implementação de novos 
procedimentos, sejam eles registrados ou não em documentos que desvelem a sua arte, os seus saberes e as suas controvérsias. É interessante destacar que é a prática assistencial o cerne da pesquisa; é ai que os conhecimentos sistematizados e repassados são testados face aos desafios da realidade e perspectivas de mudanças através das instituições de ensino. Assim a pesquisa em enfermagem tem duas interfaces básicas: a primeira, relativa ao fazer assistencial, esteja ele sistematicamente documentado ou não; a segunda, destaca a utopia da Enfermagem à luz da compreensão teórica; é o saber que ela tem ou um dia terá disponivel na prática.

A enfermagem tem um processo de registro de sua prática assistencial insuficiente. Isso acarreta uma perda do conhecimento produzido na prática, cujo resgate só ocorrerá através das pesquisas, quase sempre desvinculadas da própria prática e sem respostas consideráveis para o seu dia-a-dia.

É preciso, no entanto, que se tome consciência da importância da pesquisa científica no cotidiano da enfermagem, a fim de que ocorram mudanças efetivas na assistência. Segundo Westrupp (1994), a pesquisa deve abranger os aspectos preventivos e curativos do processo saúde-doença, cujos resultados obtidos instrumentalizem a própria prática, face ao compromisso com o desenvolvimento da profissão, a melhoria da qualidade de vida da população e o desenvolvimento científico-tecnológico.

Observamos que as colocações apresentadas por aquelas enfermeiras são as mesmas colocadas hoje pelas enfermeiras assistenciais que desejam realizar investigação (Cassiani,1994). Entretanto a diferença fundamental reside no fato de que, para as docentes, houve uma exigência e, para as assistenciais, partese de uma necessidade interna que nem sempre encontra apoio e estímulo. Quiçá tenhamos agora com um grupo que pretende com que a pesquisa transforme a prática, um novo direcionamento não servindo como um momento de dissociações nem desvinculações com o serviço tal qual as enfermeiras da década de 70 vivenciaram.

\section{REFERÊNCIAS BIBLIOGRÁFICAS}

1. ABEn/CNPq II Seminário Nacional sobre Ensino de Pós-graduação e Pesquisa em Enfermagem, 1982 Brasilia.

2. ALCÂNTARA, G. A enfermagem moderna como categoria profissional: obstáculos à sua expansão na sociedade brasileira. Ribeirão Preto,1963 125p, Tese (Cátedra) - EERP-USP.

3. ALMEIDA, M.C.P. A construção do saber na enfermagem: evolução histórica, IN: 3․ Seminário Nacional da Pesquisa em Enfermagem. 
4. ANGERAMI, E.L.S., 40 anos, a maturidade conquistada, R. Lat. Amer. Enferm. São Paulo, v.2, n.1, p.5-20,jul.1993.

5. CASSIANI, S.H.B. Buscando significado para o trabalho: o aperfeiçoamento profissional sob a perspectiva de enfermeiras; Ribeirão Preto, 1994. 197p.Tese (Doutorado) - EERP-USP.

6. CASSIANI,S.H.B., A coleta de dados nas pesquisas em enfermagem: estratégias, validade e confiabilidade; Ribeirão Preto, 1987. 151p, Tese (Mestrado) - EERP-USP.

7. LOPES, C.M. Produção de conhecimento por enfermeiros assistenciais sua utilização na prática. Ribeirão Preto, 1990. 186p. Tese (Doutorado) EERP-USP.

8.

A produção dos enfermeiros assistenciais em relação à pesquisa em Enfermagem em um Município paulista. Ribeirão Preto, 1983. Tese (Mestrado) - EERP-USP.

9. LUDKE, M. \& ANDRÉ, M.E.D.A., Pesquisa em educação: abordagens qualitativas. São Paulo: E.P.U., 1986.98p.

10. MENDES I.A.C. Pesquisa em Enfermagem: Impacto na Prática, São Paulo: EDUSP,1991. 153p.

11. PAIXĀO, W. História da Enfermagem. 5. ed. Rio de Janeiro: Julio Reis, 1970.

12. RICCI, W.Z. A pesquisa científica sob a perspectiva do aluno de graduação dos cursos de Farmácia e Enfermagem. Ribeirão Preto,1994 Monografia, 15p.

13. SOUZA, M.F. de. Tendências da pesquisa em enfermagem, R. Esc. Enferm. USP, São Paulo, v.26, n. especial, p.79-86, out.1992. 